Development of a pilot health related quality of life... Sri Lanka Journal of Child Health, 2016; 45(3): 163-168

$\underline{\text { Original Articles }}$

\title{
Development of a pilot health related quality of life tool for Sri Lankan children with epilepsy
}

\author{
*Roshini Murugupillai ${ }^{1}$, Jithangi Wanigasinghe ${ }^{2}$, Ravi Muniyandi ${ }^{3}$, Carukshi Arambepola ${ }^{4}$ \\ Sri Lanka Journal of Child Health, 2016; 45(3): 163-168
}

\begin{abstract}
Introduction: Health related quality of life (HRQL) is used as an outcome measure to describe the disease burden in epilepsy.
\end{abstract}

Objective: To develop a multidimensional questionnaire to assess the HRQL of children and adolescents with epilepsy (CAWE) in rural Sri Lanka from their primary caregiver's opinion.

Method: To generate items for pilot questionnaire, we conducted a qualitative study comprising 24 indepth interviews with 13 primary caregivers of CAWE, 5 CAWE, 3 siblings of CAWE, 3 parents of healthy children, and 3 focus group discussions with 1 primary caregiver of CAWE and 2 key informants in 3 districts (Ampara, Monaragala, Hambantota) representing a multi-ethnic rural community in Sri Lanka. Constant comparison analysis of the interview transcripts was done manually. Construct utilized to develop the pilot questionnaire was HRQL corresponding to the impact of epilepsy and its treatment on daily life based on the primary caregivers' assessment. From the qualitative data, 100 items distributed in 4 domains of HRQL was pooled initially. A 10 member expert panel did item reduction and observed content and face validity.

Results: The pilot questionnaire was composed of 34 questions in the 0-5 year age group and 60 questions in the 6-18 year age group. All items established good face and content validity.

${ }^{1}$ Lecturer, Eastern University, Sri Lanka, ${ }^{2}$ Senior Lecturer \& Honorary Paediatric Neurologist, University of Colombo, ${ }^{3}$ Senior Lecturer, Eastern University, ${ }^{4}$ Sri Lanka, Senior Lecturer \&Specialist in Community Medicine, University of Colombo

*Correspondence: muru_roshi@yahoo.com

(Received on 15 September 2015: Accepted after revision on 23 October 2015)

The authors declare that there are no conflicts of interest

Funded by World Bank.

Open Access Article published under the Creative

Commons Attribution CC-BY (CC) (P) License.
Conclusion: This pilot questionnaire appears to be unique, culturally sound and population specific HRQL tool for children and adolescents with epilepsy in rural Sri Lanka.

DOI: http://dx.doi.org/10.4038/sljch.v45i3.8024

(Key words: Quality of life, health related quality of life, epilepsy, children, adolescent).

\section{Introduction}

Globally patient care has turned from treatment and its direct outcome (improvement of the disease/ survival) to a more holistic approach of the patient wellbeing in physical, mental \& social aspects ${ }^{1}$. Assessment of health related quality of life (HRQL) is increasingly incorporated into clinical practice $^{2}$. Measurement of quality of life (QOL) outcomes is of potential value in evaluating interventions, comparing outcomes in clinical trials, commissioning programmes of care, assessing outcomes of new treatments and audits ${ }^{3-6}$.

The World Health Organization (WHO) defines QOL as "the individual's perception of their position in life, in the context of culture and value systems in which they live and in relation to their goals, expectations, standards, and concerns" $"$. This multidimensional concept follows from their widely accepted definition of 'health' as "a state of complete physical, mental, and social wellbeing and not merely the absence of disease or infirmity". HRQL is defined as an individual's subjective perception of the impact of health status on physical, psychological, and social functioning? There are several generic and epilepsy specific HRQL instruments with defined validity and reliability for use in adults and children with epilepsy. These are mostly from the developed countries. Although there are several QOL tools, it is not always possible to directly use them cross culturally due to transcultural variations and a simple translation of the QOL tool is not always appropriate $^{10}$. Only few studies have evaluated QOL issues among Asian children, mainly due to lack of culturally acceptable and reliable QOL questionnaires $^{11}$. To date, there is no culturally sound, population specific HRQL instrument for adults or children with epilepsy in Sri Lanka. 
Development of a pilot health related quality of life... Sri Lanka Journal of Child Health, 2016; 45(3): 163-168

While recommending that children should rate their own HRQL whenever possible, there are situations where proxy information may be useful, especially when a child is too ill or young ${ }^{12}$. The parental perspective, too, is important in child's health care decisions. Children may not be able to assess their HRQL accurately and reliably ${ }^{13}$ due to difficulties in understanding the questions, ability to complete lengthy questionnaires, lack of understanding of the disease or time perception differences ${ }^{14,15}$. Hence, parallel reporting is encouraged with analogous questionnaires for children and their parents ${ }^{16}$.

\section{Objective}

To develop a multidimensional questionnaire to assess the HRQL of children and adolescents with epilepsy (CAWE) in a rural community in Sri Lanka from their primary caregiver's view.

\section{Method}

The construct used to develop the pilot questionnaire was HRQL corresponding to the impact of epilepsy and its treatment on daily life of CAWE based on their primary caregivers' assessment. HRQL means asking the patient (in this case, the primary caregiver of the patient) about the perceived state of wellbeing and the impact of the disease (epilepsy) at several domains. We decided to focus on the HRQL aspects that are modifiable by medical decision or health policies. Thus we did not include social, economic and environmental aspects that refer to the entire population and not specifically to the patient, though related to the WHO conceptualization of QOL.

To identify the items for the questionnaire, we selected a qualitative study design. It offers an effective method to study the experiences from the individual's point of view ${ }^{17}$, while generating culturally specific, contextually rich and meaningful data. It also allows deeper exploration of issues that cannot be obtained through quantitative methods ${ }^{17}$. We conducted in-depth interviews with CAWE, their primary caregivers and siblings, and parents of healthy children to establish an in-depth understanding of what they experienced in their socio-cultural context. Although we intended to develop a primary caregiver proxy measure, we assumed that by including CAWE in the study, we would get an insight into the HRQOL issues deemed important by them and not miss any items that might not otherwise be elucidated by primary caregivers alone. Also, inclusion of their siblings was to understand the family functioning from their perspective. We also conducted focus group discussion (FGD) with groups of primary caregivers of children and adolescents with epilepsy and key informants such as schoolteachers and public health staff i.e. medical officer of health, public health nursing sister, public health midwives and child probation officers. We assumed that including key informants would help in exploring the HRQOL issues of CAWE from different perspectives of entities in the same socio-cultural context.

Study was carried out in Ampara, Monaragala and Hambantota districts, which represent a multiethnic, rural community in Sri Lanka. Ethical approval was obtained from the Ethics Review Committee of the Faculty of Medicine, University of Colombo. Purposeful sampling technique was used to achieve maximum variation within the sample. Sample size was determined during the research process on the basis of theoretical saturation point. This is a point in the data collection where conducting further interviews no longer bring additional insights to the research question $^{17}$.

CAWE aged 0-18 years were identified from the paediatric and adult clinics at state hospitals in each district. We included them regardless of the type and duration of epilepsy and co-morbid illnesses such as cerebral palsy to study the complete spectrum of HRQOL issues related to epilepsy. Participants were contacted by phone or through public health midwife and were invited to participate in the study. All interviews were held in participants' houses. Siblings aged 6-18 years were identified during the home visits. Children less than 6 years of age were assumed not able to have an effective conversation in an in-depth interview. Parents of healthy children were selected from the neighbourhood of the children with epilepsy during the field visits.

Invitation to participate in FGD was sent to teachers in a school and those who expressed willingness were recruited. Public health staffs such as medical officer of health, public health nursing sister, public health midwives and child probation officers attached to Kalmunai $\mathrm{MOH}$ were also invited. FGDs were conducted at a common place such as community centre for primary care givers, classroom for teachers or $\mathrm{MOH}$ office for public health staff. Informed written consent was sought before conducting in-depth interviews and FGDs. For children, consent was taken from their parents. Data were gathered using standard procedures for in-depth interviews and FGDs ${ }^{17}$. Primary author conducted all interviews and FGDs using pre-tested, semi structured interviewer guide. All interviews were conducted face-to face. Participants were asked open-ended questions to explore the impact of epilepsy on children's lives. Details of conducting in-depth interviews and FGDs are not discussed here as it is out of the 
Development of a pilot health related quality of life... Sri Lanka Journal of Child Health, 2016; 45(3): 163-168

scope of this paper. Interviews were conducted in the main dialects Tamil and Sinhala. Interviews were audio-recorded, later transcribed verbatim into local languages. Transcripts were then translated into English.

Primary author analysed the data manually using constant comparison analysis approach ${ }^{18}$. After data cleaning and data familiarization, open coding was done. During this process data were cut into smaller units and a code (or descriptor) was given to each unit. Thereafter, the codes were grouped into categories that describe similar content (axial coding). Lastly, themes were developed that express the content of each of the categories (selective coding). An independent investigator double coded about $10 \%$ of data to minimize bias in analysis. Variation in coding was reviewed in a meeting to reach consensus.

Major themes that arose from the qualitative analysis formed the domains for the questionnaire. Items that were deemed important by the participants were identified and pooled under each domain. We identified 100 items and compiled them into a self-administered questionnaire in English language.

A 10 member expert panel reviewed the questions individually. The expert panel comprised 3 paediatricians (from academic and clinical set up), 2 paediatric neurologists, child psychiatrist, community physician, public health expert, clinical psychologist and sociologist. Considering the developmental differences that occur in different age groups, each expert in the panel was given 2 copies of the questionnaire, one for 0-5 years and the other for 6-18 years age group. They were asked to rate each item according to a five-point scale. There was a comment section at the end of the questionnaire and the experts were asked to write their observations regarding construct, content and wording of the questions and to add any missed items deemed important.

We used a quantitative method to assess the content validity of the items ${ }^{19}$. Content validity ratio (CVR) was calculated for each item. For each item in both age group questionnaires, both values of CVR (strict) and CVR (relaxed) were calculated. We used CVR values to decide on which items to include or remove ${ }^{20}$. Only items equal or above the specified critical value were included in the questionnaire. For a panel size of 10 , the critical number of experts was 9 , and the critical CVR value was 0.8 . We opted to use CVR (relaxed) values to have a substantial number of items in each domain ${ }^{20}$.
Considering the comments given by the expert panel, items were critically reviewed for difficulty, ambiguity, jargons, duplicates, moral judgments and negative feelings. Items were then modified, removed or moved within domains. A new item suggested by the expert panel on anti-epileptic drug use during inter-current illnesses was added to both age groups. Questionnaires were then translated into Sinhala and Tamil languages. Items had five possible answers, scored one to five. Domains were equally weighted by means of per cent scores. They were then fed back to two parents who took part in the in-depth interviews to review readability and appropriateness from their perspective.

\section{Results}

A total of 24 in-depth interviews and 3 FGDs were conducted. Participant characteristics for in-depth interviews and FDGs are given in Table 1 and Table 2.

Table 1: Participant characteristics Parents of epileptic children $(n=13)$

\begin{tabular}{|c|c|}
\hline \multicolumn{2}{|c|}{ Parents of epileptic children $(n=13)$} \\
\hline Gender & $\begin{array}{c}\text { Male } 2: \text { Female } \\
11\end{array}$ \\
\hline Age & $28-54$ years \\
\hline Educational level & \\
\hline Never attended school & 04 \\
\hline Grade 5 and below & 02 \\
\hline Grade 6-10 & 06 \\
\hline Completed advanced level & 01 \\
\hline \multicolumn{2}{|c|}{ Children with epilepsy $(n=5)$} \\
\hline Gender & Male 3 : Female 2 \\
\hline Age & $13-18$ years \\
\hline Age at onset (Range) & 3 days -7 years \\
\hline Seizure type & \\
\hline Simple partial & 03 \\
\hline Generalized tonic clonic & 01 \\
\hline Absence seizure & 01 \\
\hline Seizure frequency & \\
\hline$>1$ per month & 01 \\
\hline$>1$ per year & 03 \\
\hline No seizures & 01 \\
\hline Medication & \\
\hline Sodium valproate & 05 \\
\hline Educational status & \\
\hline Mainstream school & 05 \\
\hline \multicolumn{2}{|l|}{$\begin{array}{l}\text { Siblings }(n=3) \\
\end{array}$} \\
\hline Gender & Male 1 : Female 2 \\
\hline Age & $6-15$ years \\
\hline Educational level & \\
\hline Grade 5 and below & 01 \\
\hline Grade 6-10 & 02 \\
\hline \multicolumn{2}{|c|}{ Parents of healthy children $(n=3)$} \\
\hline Gender & Male 1 : Female 2 \\
\hline Age & $34-45$ years \\
\hline $\begin{array}{l}\text { Educational level } \\
\text { Grade } 10 \text { and below }\end{array}$ & 03 \\
\hline
\end{tabular}


Development of a pilot health related quality of life... Sri Lanka Journal of Child Health, 2016; 45(3): 163-168

Table 2: Composition of focus groups

\begin{tabular}{|l|l|}
\hline Focus group & Number of participants \\
\hline Primary care givers & $5($ All female $)$ \\
\hline School teachers & $8($ male -4, female -4$)$ \\
\hline Public health staff & $10($ male -4, female -6$)$ \\
\hline
\end{tabular}

Themes and categories emerged from the qualitative data analysis are presented in Table 3.

Table 3: Themes and categories

\begin{tabular}{|c|c|}
\hline $\begin{array}{l}\text { Child's physical } \\
\text { functioning } \\
\text { Growth \& development } \\
\text { Self-care } \\
\text { Liveliness } \\
\text { Restrictions to physical } \\
\text { activities }\end{array}$ & $\begin{array}{l}\text { Child's } \\
\text { functioning } \\
\text { Family } \\
\text { Relationships } \\
\text { Participation } \\
\text { Imposed restrictions }\end{array}$ \\
\hline $\begin{array}{l}\text { Child's psychological } \\
\text { functioning } \\
\text { Cognition } \\
\text { Learning difficulties } \\
\text { Behavioural problems } \\
\text { Emotions }\end{array}$ & $\begin{array}{l}\text { Child's general well- } \\
\text { being } \\
\text { Drug effect } \\
\text { General health } \\
\text { Quality of life* }\end{array}$ \\
\hline
\end{tabular}

* Added from the literature.

Emerged themes were used to form the domains of the pilot HRQL questionnaire. We identified 100 items distributed among these domains. After item reduction, 40 items in the $0-5$ year age group and 81 items in the 6-18 year age group were retained. Following critical review of the items, the final questionnaire contained 34 items in the $0-5$ year and 60 items in 6-18 years age groups. Items were distributed into 4 domains: physical functioning $(7 ; 9)$, psychological functioning $(7 ; 31)$, social functioning $(19 ; 19)$ and general well-being $(1 ; 1)$ domains.

\section{Discussion}

Standard measures to assess HRQL in children with epilepsy are lacking in Sri Lanka. Based on the items generated from the population, we developed 2 age specific proxy measures of HRQL for children with epilepsy. Face and content validity of items were confirmed, as the sample population in the qualitative study identified these items as HRQL issues ${ }^{21}$. Also, good face validity was found from the expert panel and content validity was established through $\mathrm{CVR}^{20}$. Construct validity of any QOL questionnaire depends on the exact definition of QOL used ${ }^{3}$. We selected the HRQL definition since it is directly relevant to clinical practice and related to aspects in which health professionals may interfere.

We developed questionnaires for $0-5$ and 6-18 years age groups, to match with children's age related experiences, activities, and contexts and ensured that items correspond to these elements ${ }^{22}$. By using the phrase 'because of epilepsy...' in the sentences where appropriate, we clarified that we were interested in the perception of how epilepsy, and no other condition affects the HRQL.

Domains in our pilot questionnaire were comparable to the domains of other HRQL tools for children ${ }^{12,21,23}$. However, our questionnaire appears unique and culturally sound as it was developed from the population concerned. In particular, items pertaining to physical appearance, body image and intimate relationships of adolescents $^{12,21,23}$ were few that were not identified as important issues by our population in this study.

The psychometric properties of any instrument are essential to determine if the measure is acceptable for clinical purposes. The pilot questionnaires for both age groups are now undergoing validation study in a selected population.

Since there are transcultural differences in adapting items from a tool developed elsewhere, we believe that generating items from our population was a strength to our study. Also, using qualitative methods allowed us to explore the contents indepth.

Deciding for the primary caregiver assessment was controversial because a proxy report is inconsistent with the concept of HRQL, which is based on the patient's subjective assessment. Difficulty for younger ages to give reliable response on complex or abstract health-related constructs being a disadvantage of child-report, parent report may have greater reliability ${ }^{22}$ and the parent's perspective is as important in HQRL assessment because of the dependent nature of the parent-child relationship. However, one should be cautious in interpreting proxy measure, as it might not capture the whole perception of how children perceive their own HRQL ${ }^{21}$.

\section{Conclusions}

Pilot proxy HRQL tools for children with epilepsy aged $0-5$ and 6-18 years were successfully developed. Face validity and preliminary content validity were established. The questionnaires are undergoing validation study to determine the psychometric properties.

\section{Acknowledgement}

We acknowledge the World Bank for providing the funds by Higher Education for Twenty first Century - Quality and Innovative Grant - Window 3 (HETC QIG W3), to conduct this study.

\section{References}

1. Davis E, Waters E, Mackinnon A, Reddihough D, Graham HK, MehmetRadji O, et al. Paediatric quality of life 
Development of a pilot health related quality of life... Sri Lanka Journal of Child Health, 2016; 45(3): 163-168

instruments: a review of the impact of the conceptual framework on outcomes. Developmental Medicine \& Child Neurology 2006; 48:311-8. http://dx.doi.org/10.1017/S001216220600 0673

PMid: 16542522

2. Ronen GM, Streiner DL, Verhey LH, Lach L, Boyle MH, Cunningham CE, et al. Disease characteristics and psychosocial factors: Explaining the expression of quality of life in childhood epilepsy. Epilepsy \& Behavior 2010; 18:88-93.

http://dx.doi.org/10.1017/S001216220600

0673

PMid: 16542522

3. Filho MHS, Gomes MM, Fontenelle LMC. Development and validation of a health related quality of life questionnaire for Brazilian children with epilepsyPreliminary findings. Arq Neuropsiquiatr. 2005; 63(2-B):389-94.

http://dx.doi.org/10.1590/S0004282X2005 000300004

4. Eiser C, Morse R. A review of measures of quality of life for children with chronic illness. Archives of Disease in Childhood 2001; 84:205-11.

http://dx.doi.org/10.1136/adc.84.3.205

PMid: 11207164 PMCid: PMC1718699

5. Neumann PJ, Goldie SJ, Weinstein MC. Preference-based measures in economic evaluation in health care. Annual Review of Public Health 2000; 21:587-611.

http://dx.doi.org/10.1146/annurev.publhea 1th.21.1.587

PMid: 10884966

6. Hyland ME. Quality-of-life measures as providers of information on value-formoney of health interventions. Comparison and recommendations for practice. Pharmacoeconomics 1997; 11: 19-31.

http://dx.doi.org/10.2165/0001905319971

1010-00004

PMid: 10172916

7. World Health Organization. Measuring quality of life. The world health organization quality of life instruments (The WHOQOL - 100 and The WHOQOL - BREF). Division of mental health and prevention of substance abuse. World Health Organization; 1997.
8. World Health Organization. World Health Organization Constitution. Geneva: World Health Organization; 1947.

9. Leidy NK, Rich M, Geneste B. Recommendations for evaluation the validity of quality of life claims for labelling and promotion. Value Health 1999; 2:113-27.

http://dx.doi.org/10.1046/j.15244733.1999 .02210.x

PMid: 16674343

10. Streiner DL, Norman GR. Health measurement scales. A practical guide to their development and use. Oxford: Oxford Univ Press: 1989.

http://dx.doi.org/10.1046/j.15244733.1999 .02210.x

PMid: 16674343

11. Wee HL, Sieberer UR, Erhart M, Li SC. Factor structure of the Singapore English version of the KINDL ${ }^{\circledR}$ children quality of life questionnaire. Health and Quality of Life Outcomes 2007; 5:4.

http://dx.doi.org/10.1186/1477-7525-5-4

PMid: 17239229 PMCid: PMC1796858

12. Hutchings HA, Upton $\mathrm{P}$, Cheung WY, Maddocks A, Eiser C, Williams JG, et al. Development of a parent version of the Manchester-Minneapolis quality of life survey for use by parents and carers of UK children: MMQL-UK (PF). Health and Quality of Life Outcomes 2008; 6:19. http://dx.doi.org/10.1186/1477-7525-6-19 PMid: 18307771 PMCid: PMC2270806

13. Connolly MA, Johnson JA. Measuring quality of life in paediatric patients. Pharmacoeconomics 1999; 6(6):605-25. http://dx.doi.org/10.2165/00019053199916060-00002

14. Marra CA, Levine $M$, McKerrow R, Carleton BC. Overview of health-related quality-of-life measures for paediatric patients: application in the assessment of pharmacotherapeutic and pharmacoeconomic outcomes. Pharmacotherapy 1996; 16(5):879-88.

PMid: 8888083

15. Mulhern RK, Horowitz ME, Ochs J, Freidman AG, Armstrong FD, Copeland $\mathrm{D}$, et al. Assessment of quality of life among paediatric patients with cancer. Psychological Assessment 1989; 1:130-8. 
http://dx.doi.org/10.1037/10403590.1.2.13

0

16. Jokovic A, Locker D, Guyatt G: How well do parents know their children? Implications for proxy reporting of child health related quality of life. Quality of Life Research 2004; 13:1297-307. http://dx.doi.org/10.1023/B:QURE.00000 37480.65972.eb

17. Mack N, Woodsong C, Macqueen KM, Guest G, Namey E. Qualitative Research Methods: A Data Collector's Field Guide. ISBN: 0-939704-98-6. North Carolina (USA). Family Health International; 2005.

18. Strauss A, Corbin J. Basics of qualitative research: Techniques and procedures for developing grounded theory. Thousand Oaks, CA: Sage; 1998.

19. Lawshe $\mathrm{CH}$. A quantitative approach to content validity. Personnel Psychology 1975; 28:563-75.

http://dx.doi.org/10.1111/j.17446570.1975 .tb01393.x

20. Brinkman WP. Preliminary version of: Design of a Questionnaire Instrument, Handbook of Mobile Technology Research Methods. ISBN 978-1-60692767-0, pp. 31-57, Nova Publisher; 2009.
21. Ronen GM, Streiner DL, Rosenbaum P. Health-related quality of life in children with epilepsy: Development and validation of self-report and parent proxy measures. Epilepsia 2003; 44(4):598-612 http://dx.doi.org/10.1046/j.15281157.2003 .46302.x

PMid: 12681011

22. Matza LS, Swensen AR, Flood EM, Secnik K, Leidy NK. Assessment of Health-Related Quality of Life in Children: A Review of Conceptual, Methodological, and Regulatory Issues. Value Health 2004; 7(1):79-92. http://dx.doi.org/10.1111/j.15244733.2004 .71273.x

PMid: 14720133

23. Varni JW, Seid M, Kurtin PS. PedsQL ${ }^{\mathrm{TM}}$ 4.0: Reliability and validity of the pediatric quality of life inventory ${ }^{\mathrm{TM}}$ version 4.0 generic core scales in healthy and patient population. Med Care 2001; 39(8):800-12.

http://dx.doi.org/10.1097/0000565020010 8000-00006

PMid: 11468499 